Mota Oksana, Halyuk Ulyana, Pokotylo Petro, Lohash Maxim, Zboina Bożena, Ślusarska Barbara, Król Halina, Czerwińska Pawluk Iwona, Zukow Walery. The Morphometric Analysis of the Human Thyroid of the Endemic Region of Ukraine. Journal of Education, Health and Sport. 2020;10(1):101-112. eISSN 2391-8306. DOI http://dx.doi.org/10.12775/JEHS.2020.10.01.012 https://apcz.umk.pl/czasopisma/index.php/JEHS/article/view/JEHS.2020.10.01.012 https://zenodo.org/record/3628894

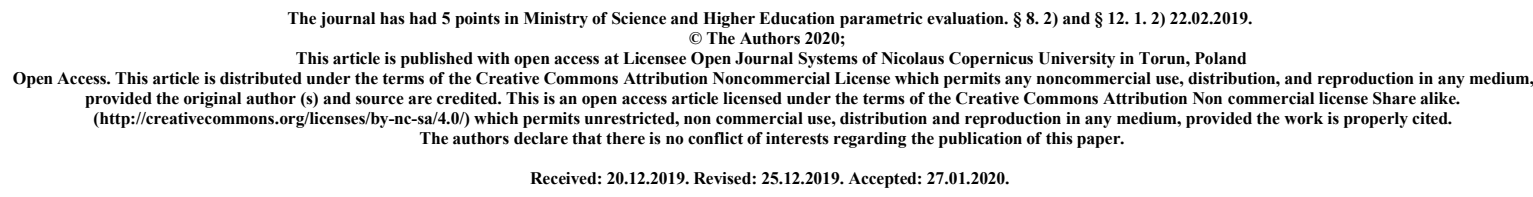

UDC: $611.641 \quad 018.1: 616 \quad 053.6(477.87)$

\title{
The Morphometric Analysis of the Human Thyroid of the Endemic Region of Ukraine
}

\section{Oksana Mota ${ }^{1}$, Ulyana Halyuk ${ }^{1}$, Petro Pokotylo, Maxim Lohash ${ }^{1}$, Bożena Zboina ${ }^{2}$, Barbara Ślusarska ${ }^{3}$, Halina Król ${ }^{4}$, Iwona Czerwińska Pawluk ${ }^{5}$, Walery Zukow ${ }^{6}$}

\author{
${ }^{1}$ Department of Normal Anatomy, Lviv National Medical University, Danylo Halycky, Lviv, Ukraine \\ ${ }^{2}$ Department of Pedagogy and Health Sciences, College of Business and Entreprise, Ostrowiec Świetokrzyski, \\ Poland \\ ${ }^{3}$ Department of Family Medicine and Community Nursing, Chair of Oncology and Environmental \\ Health, Faculty of Health Sciences, Medical University of Lublin, Poland \\ ${ }^{4}$ Institute of Public Health, Faculty of Medicine and Health Sciences, The Jan Kochanowski University in \\ Kielce, Poland \\ ${ }^{5}$ Radom College in Radom, Faculty of Health Sciences, University of Children's Hospital Lublin, Poland \\ ${ }^{6}$ Nicolaus Copernicus University, Toruń, Poland
}

Oksana Mota Kaf normanatomy@,meduniv.lviv.ua

Ulyana Halyuk Kaf normanatomy@meduniv.lviv.ua

Petro Pokotylo anatompetro@gmail.com

Maxim Lohash Kaf normanatomy@meduniv.lviv.ua

Bożena Zboina 0000-0003-1245-5451 bozenazboina@poczta.fm

Barbara Ślusarska 0000-0003-0101-9216 basiaslusarska@gmail.com

Halina Król 0000-0001-6716-6185 krolhalina@poczta.fm halina.krol@ujk.edu.pl

Iwona Czerwińska Pawluk elwira64@wp.pl

Walery Zukoww.zukow@wp.pl

\footnotetext{
Abstract

Introduction. Since the thyroid gland (TG), like the rest of the human body, is characterised by wide variety in shape and size, the evaluation of its linear and volumetric parameters by ultrasound images is one of the most important and objective ways of quantitative characteristics of the organ. There are scarce studies into TG morphometry by ultrasound in the Precarpathian region, which is one of the oldest endemic places in Europe.
} 
Objective. The aim of the current research study is to conduct the morphometric analysis of TG in adolescents of different sex and constitution who are indigenous inhabitants of the Precarpathian region

Materials and methods. Therefore, the morphometric analysis of TG linear and morphometric parameters has been conducted in 179 adolescents inhabiting the territory. Ultrasonography has been carried out in Lviv Regional Infectious Clinical Hospital by means of "CHISON" sonograph. Three longitudinal and three anteroposterior dimensions of TG right and left lobes at different levels were measured based on the sonograms taken UDC: $611.641018 .1: 6$ at the angle of $20-30^{\circ}$ to the median plane. The volume of each TG lateral lobe was measured by the following formula: $\mathrm{AxBxCx} 0.52$, where $\mathrm{A}$ is the lobe length, $\mathrm{B}$ is the lobe width, $\mathrm{C}$ is the lobe thickness, and 0.52 is the coefficient of allowance.

Results. The ratio between the linear parameters of the lobes has been revealed to be determined rather by constitutional than by sex peculiarities of those under study. It is statistically probable that longitudinal dimensions of both lobes in dolichomorphic people of both sexes exceed the analogous ones in mesomorphs and brachymorphs of both sexes. TG lobes in brachymorphs, in particular, are wider compared with those in both mesomorphs and dolichomorphs, irrespective of sex. The analysis of TG volumetric parameters in different body types of both sexes has indicated that TG volume in brachymorphs dominates in volume over mesomorphs and dolichomorphs, irrespective of sex. Moreover, the volume of the right lobe is larger than the volume of the left one by $0.5-1.0 \mathrm{~cm}^{3}$ in all of the body types of both sexes. The difference is especially marked in males of the brachymorphic body type. Although there is no statistically probable difference in male and female TG volumes of mesomorphs and dolichomorphs. TG volumes in male brachymorphs are markedly larger than in female ones. As for volume variations they are quite extensive from a minimal male TG volume of $4.85 \mathrm{~cm}^{3}$ to a maximal one of $17.52 \mathrm{~cm}^{3}$, and from a minimal female TG volume of $3.09 \mathrm{~cm}^{3}$ to a maximal one of $14.51 \mathrm{~cm}^{3}$.

Conclusions. Thuse the results of TG morphometry by ultrasound demonstrate that there is a direct correlation between TG linear, volumetric parameters and sex or body types, which should be taken into consideration while making a diagnosis in order to avoid incorrect positive diagnoses of TG hypo- or hyperplasia.

Key words: thyroid gland; ultrasound investigation; morphometric analysis; sex; constitution body type

\section{INTRODUCTION}

The development of two-dimensional sonography, apart from descriptive investigations, quantitative ones into the thyroid gland (TG). Since TG, like the rest of the human body, is characterised by wide variety in individual shape and size, the evaluation of its linear and volumetric parameters by ultrasound investigation is one of the most important and objective ways of quantitative characteristics of the organ. High resolution and absolute safety of ultrasound in almost age groups, as well as the possibility of gradual accumulation of TG ultrasound data accompanied by its dynamic assessment, determine ultrasound appropriateness not only to diagnose, but also to study the anatomical features of TG, taking into account both exogenous and endogenous factors. Previous TG ultrasound investigations reveal that linear and volumetric parameters correlate with age, sex, height and weight, place of residence and use of hormonal drugs $[1,2]$. Some researchers suppose that the higher rates of psysical development of children and teenagers (mostly linked to the economic development and nutritional factors) the higher the number with normal TG [3, 4]. As for TG morphometry, there are scarce studies by ultrasound in the Precarpathian region, which is one of the oldest endemic places in Europe $[5,6]$. Furthurmore, most researches limit their 
investigations into TG linear parameters into length, width and thickness of each lobe followed by the calculation of TG volume $[1,7]$. Unfortunately, there is hardly any available literature on TG morphometry at the system level dealing with the measurement of longitudional and anteroposterior dimensions of TG right and left lobes at different levels. However, we believe that such measurements of linear parameters of right and left lobes at different levels have profound clinical implications for TG morphometry. They are determined by the following features: 1) the dependence of the lobe shapes on sex and constitution; 2) the possibility of initial hyperplasia or focal pathology in TG lobes. In addition to that, it should be noted that morphometry as a science has been created and widely used by morphologists [3], but it is badly know by clinicians and as a result, rarely used by them. Besides, another matter of importance is the ability to compare ultrasound results presented by other researches.

\section{OBJECTIVE}

The overall aim of the current research study is to conduct the morphometric analysis of TG in adolescents of different sex and constitution who are indigenous inhabitants of the Precarpathian region.

\section{MATERIALS AND METHOD}

The selection criteria for the study served: 179 people ( 85 males and 94 females) aged from 16 to 21 have been examined by ultrasound; the constitutional types (dolichomorphic, mesomorphic and brachymorphic); all the examined were indigenous inhabitans of the Precarpathian region. The ultrasound investigation was carried out in Lviv Regional Infectious Clinical Hospital by means of "CHISON" sonograph. We used the convex transdyuser with an operating frequency of $7.5 \mathrm{Mhz}$ without a water nozzle. The device settings for all the studies remained unchanged. "Sonogel" was applied to the area of the neck for full contact of the sensor with the surface of the skin. Three longitudinal and three anteroposterior dimensions of TG right and left lobes at different levels were measured based on the sonograms taken at the angle of $20-30^{\circ}$ to the median plane. The following demensions of the lobes were measured: length — the maximal longitudional dimension determined along the line connecting upper and lower poles of the lobes; the front longitudinal dimension determined along the front surface of the lobes (the line which runs at a distance of $3 \mathrm{~mm}$ from the most convex point of the front surface of the lobes); the rear longitudional dimension determined along the rear surface of the lobes (the line which runs at 
a distance of $3 \mathrm{~mm}$ from the most convex point of the rear surface of the lobes). The frontdorsal dimensions of either lobe also measured at three levels: 1) at the level of the isthmus (the maximal dimension between the front and dorsal surfaces of the lobes, which is called the thickness of the lobe); 2) at the level of the upper pole (at a distance of $5 \mathrm{~mm}$ below the extreme point of the upper pole, which is called the upper front-rear dimension); 3) at the level of the lower pole (at a distance of $5 \mathrm{~mm}$ above the extreme point of the lower pole, which is called the lower front-dorsal dimension. The volume of each TG lateral lobe was measured by the formula: $\mathrm{AxBxCx} 0.52$, where $\mathrm{A}$ is the lobe length, $\mathrm{B}$ is the lobe width, $\mathrm{C}$ is the lobe thickness, and 0.52 is the coefficient of allowance. The total volume is comprised of the sum of both lobes. The thickness of the isthmus was not taken into consideration.

The constitutional types (dolichomorphic, mesomorphic and brachymorphic) were determined by such indices as the body relative length index and the shoulders relative width index. The study was undertaken in compliance with bioethics norms (Protocol 3, 2016).

Statistical analysis. Analysis of variance (ANOVA) was used to compare three or more group means for statistical significance with Tukey post-hoc test for multiply comparison. Two-way t-test for independent groups was used to compare two group means for statistical significance. The Shapiro-Wilk test was used for testing the normality of data. Data were expressed as means \pm standard error of mean (SEM). Statistical analyses were performed with RStudio Version 1.1 .442 software. A value of $p<0.05$ was considered statistically significant.

\section{RESULTS}

Analysis of the obtained experimental data on TG lobes linear parameters of both sexes of different constitutional types is shown in Table 1. The results of the morphometric analysis display that linear parameters values of the lobes are determined rather by constitutional than by sex peculiarities. It is statistically probable that longitudinal dimensions of both lobes in dolichomorphs of both sexes exceed the analogous dimensions in mesomorphs and brachymorphs of both sexes. TG lobes in brachymorphs, in particular, are wider compared with those in both mesomorphs and dolichomorphs, irrespective in sex. According to our experimental results the following relationship is characteristic of longitudinal dimensions of TG lobes of both sexes and all constitutional types: the lobe length is the maximal dimension, and the front longitudinal dimension dominate, the dorsal longitudinal dimension. The difference between those three dimensions is determined by sex and constitutional peculiarities (Fig.1, Fig.2). The difference in longitudinal dimensions of 
TG lobes in dolichomorphs is insignificant. In males, the average front longitudinal dimension exceeds the average dorsal longitudinal dimension by $3.73 \mathrm{~mm}$ in the right lobe and by $3.8 \mathrm{~mm}$ in the left one. In females, the corresponding difference is $3.00 \mathrm{~mm}$ and 2.61 $\mathrm{mm}$. The maximal difference in longitudinal dimensions of the lobes occurs in brachymorphs, irrespective of sex. In males, the front longitudinal dimension of the right lobe exceeds its dorsal longitudinal dimension by $5.48 \mathrm{~mm}$ and by $5.62 \mathrm{~mm}$ in the left lobe. In females, the corresponding difference is $5.60 \mathrm{~mm}$ and $5.37 \mathrm{~mm}$. The ratio of longitudinal dimensions of TG lobes in mesomorphs occupies the intermediate place between the other two. In males the difference between the front and dorsal longitudinal dimensions of the right lobe is $4.49 \mathrm{~mm}$ and $4.27 \mathrm{~mm}$ for the left lobe, in both lobes this difference was statistically significant $(p<0,001)$. The corresponding difference in females is $4.23 \mathrm{~mm}$ and $3.92 \mathrm{~mm}(\mathrm{p}<0,001)$. The analysis of the front-dorsal dimensions of the TG lobes (Fig. 3) reveals that the maximal difference occurs in brachymorphs, irrespective of sex, whereas the minimal one occurs in dolichomorphic males. The front-dorsal dimension at the level of the lower pole of each lobe in all constitutional types, irrespective of sex, dominates the corresponding dimension at the level of the upper pole. However, the difference is not statistically probable. The abovementioned morphometric indices manifest that TG lobes in brachymorphs are more rounded than TG lobes of othee constitutional types. Their front and posterior surfaces are convex, the posterior surface being more convex than the front one. Consequently, the front and posterior surfaces of TG lobes in dolichomorphs are flatter than the corresponding surfaces of TG lobes in both mesomorphs and brachymorphs. Their front-dorsal dimensions gradually decrease in the direction of the upper and lower poles. Analysis of TG volumetric parameters of both sexes and different constitutional types (Table 2) has revealed that TG volume in brachymorphs, irrespective of sex, dominates TG volume in both mesomorphs and dolichomorphs, but statistically significant differences was revealed only by the type between three groups $(p=0,039)$ but not in post-hoc test. Futhermore, the volume of the right lobe exceeds the volume of the left lobe in all the constitutional types by $0.5-1.0 \mathrm{~cm}^{3}(p<0,001)$. The difference is particularly marked in brachymorphic males. Compared with TG volumes in female brachymorphs there is no statistically probable difference between male and female TG volumes in both mesomorphs and dolichomorphs. As for brachymorphs, the volume of male TG is considerably higher than that of female TG. But these differences of TG volume in male and female wasn't statistically significant $(\mathrm{p}=0,014)$. TG volume variations are quite extensive: from a minimal male TG volume of $4.85 \mathrm{~cm}^{3}$ to a maximal one of $17.52 \mathrm{~cm}^{3}$, and from a minimal female TG volume of $3.09 \mathrm{~cm}^{3}$ to a maximal one of $14.51 \mathrm{~cm}^{3}$. 


\section{DISCUSSIONS}

We have been the first to develop and conduct TG morphometry by ultrasound images, including the measurement of longitudinal and anteroposterior dimensions at different levels of TG lobes. The obtained data enables us to study the structure of TG lobes more detailed, as well as reveal the dependency on the constitutional type. It should be noted that only in brachymorphs there is the statistically probable dominance of male TG volume over female TG volume. As for other constitutional types, we have not detected any difference, which is apparent contradiction to the available literature on the subject. The achieved results do not match with the results of a number of authors [6, 7] who have concluded that male TG volume always dominates over female TG volume, irrespective of the constitutional type. However, our results are close to the results of V. Klingmuller [2], a German author, who did not reveal sexual dimorphism while researching into TG volume. The scientist claims that total TG volume depends on body surface area and that the volume of the right lobe dominate the volume of the left one. Thus our results testify once again that it is necessity to establish the regional norms/regulations on linear and volumetric TG parameters taking into account the age, sex, constitution and exogenic factors into account. They can be used to study age morphology, model TG illnesses and injuries.

\section{CONCLUSIONS}

1. It has been revealed that $\mathrm{TG}$ linear dimensions and their ratios/ relationships are determined rather by constitutional than by sex peculiaruties.

2. Irrespective of sex, it is statistically probable that longitudinal lobe dimensions in dolichomorphs exceed the analogous dimensions in both mesomorphs and brachymorphs.

3. The difference magnitude in both longitudional and anteroposterior lobe dimensions increases from dolichomorphs to brachymorphs.

4. Only in brachymorphs there is the statistically probable dominance of male TG volume over female TG volume, whereas in other constitutional types the difference has not been detected.

5. Due to the considerable variations in TG volume, it cannot be adopted as a strict criterion for the detection of TG hyperplasia. However, the TG volume can serve as an important indicator of TG enlargement in a particular person re-examination. 


\section{REFERENCES}

1. Fleury Y, Van Melle G, Woringer V, Gaillard RC, Portmann L. Sex-dependent variations and timing of thyroid growth during puberty. J. Clin. Endocrinol. Metab. 2001;86 (2):750-754.

2. Klingmuller V, Fidler C, Otttn A. Characteristics of thyroid sonography in infants and children. (German) Radiologe. 1992;32(7):320-326.

3. Enshtein EV, Matiashchuk SY Ultrazvukovoe yssledovanye shchytovydnoi zhelezы. Kyev; 1996:192. (In Russian).

4. Kostyshyn N, Mota O, Kryvko Y. Anatomic and Ultrasound thyroid bodi approximation. $6^{\text {th }}$ International Simposium of Clinical and Applied Anatomy. Rijeka. Croatia. 2014:79.

5. Gunas IV, Vastyanov RS, Majevski OY. Regression models normative sonographic parameters thyroid gland depending on the characteristies of the body structure in men and women of all ages. Journal of education, health and sport. 2015;15(2):169173.

6. Tas F, Bulut S, Egilmez H, Oztoprak I, Ergur AT, Candan F. Normal thyroid volume by ultrasonography in healthy children. Ann. Trop. Paediatr. 2002;22(4):375-379.

7. Shapiro R.S. Panoramic ultrasound of the thyroid. Thyroid. 2003;13(2):177-81. 


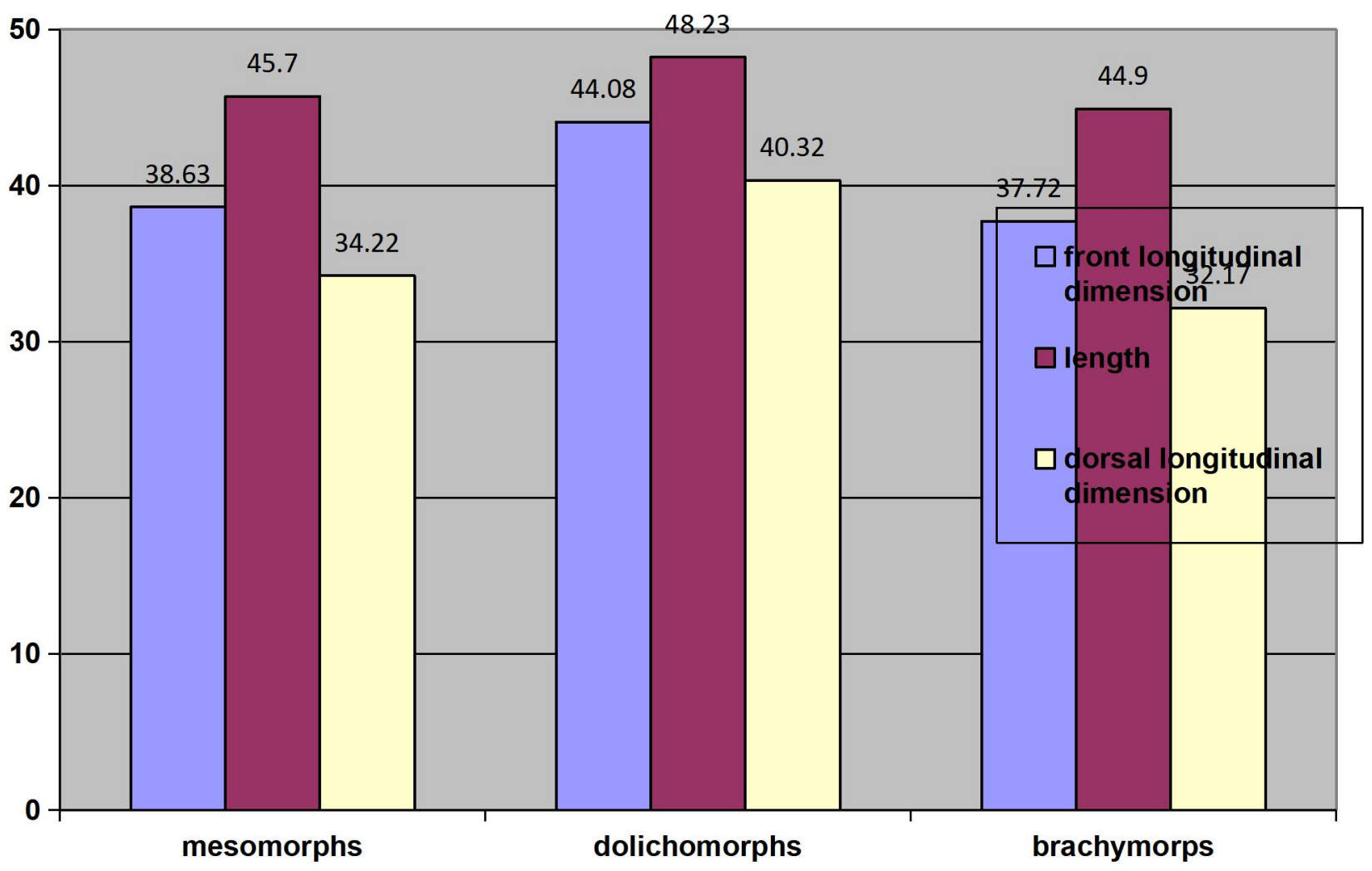

Table 2. Analysis of TG volumetric parameters of both sexes and different constitutional types, $\mathrm{M} \pm \mathrm{m}\left(\mathrm{cm}^{3}\right)$

\begin{tabular}{|l|c|c|c|c|c|c|}
\hline \multirow{2}{*}{} & \multicolumn{5}{|c|}{ constitutional types } \\
\cline { 2 - 7 } & \multicolumn{2}{|c|}{ mesomorphs } & \multicolumn{2}{c|}{ dolichomorphs } & \multicolumn{2}{c|}{ brachymorphs } \\
\cline { 2 - 7 } & $\mathrm{M}$ & $\mathrm{F}$ & $\mathrm{M}$ & $\mathrm{F}$ & $\mathrm{M}$ & $\mathrm{F}$ \\
\hline $\begin{array}{l}\text { volume } \\
\text { right lobes }\end{array}$ & $5,55 \pm 0,17$ & $5,45 \pm 0,20$ & $5,46 \pm 0,16$ & $5,48 \pm 0,16$ & $6,61 \pm 0,29^{*}$ & $6,28 \pm 0,23$ \\
\hline $\begin{array}{l}\text { volume left } \\
\text { lobes }\end{array}$ & $4,87 \pm 0,16$ & $4,64 \pm 0,16$ & $4,82 \pm 0,15$ & $4,70 \pm 0,13$ & $5,77 \pm 0,32$ & $5,24 \pm 0,20$ \\
\hline volume TG & $10,40 \pm 0,31$ & $10,10 \pm 0,34$ & $10,30 \pm 0,30$ & $10,20 \pm 0,27$ & $12,2 \pm 0,67^{*}$ & $11,24 \pm 0,43^{*}$ \\
\hline
\end{tabular}



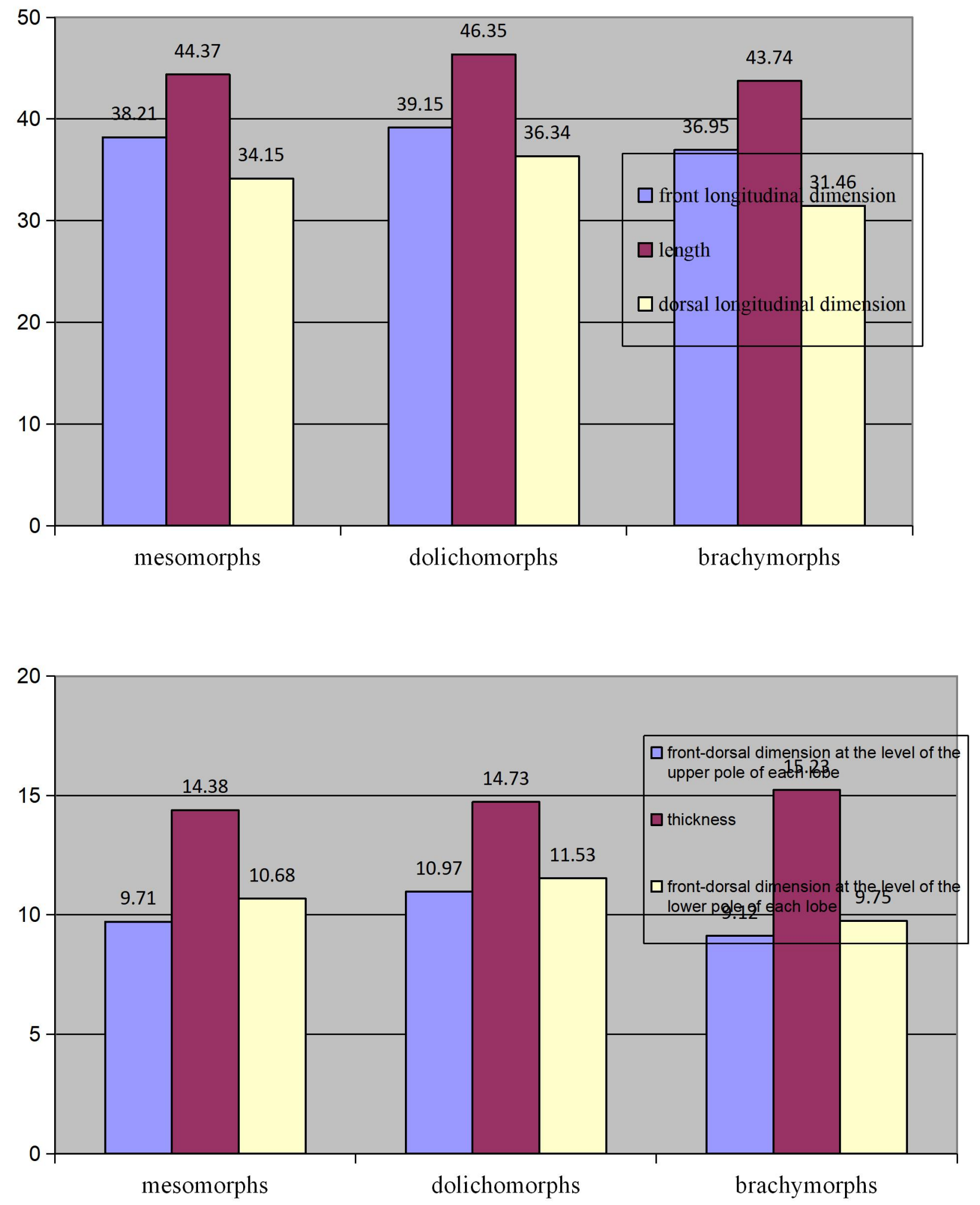


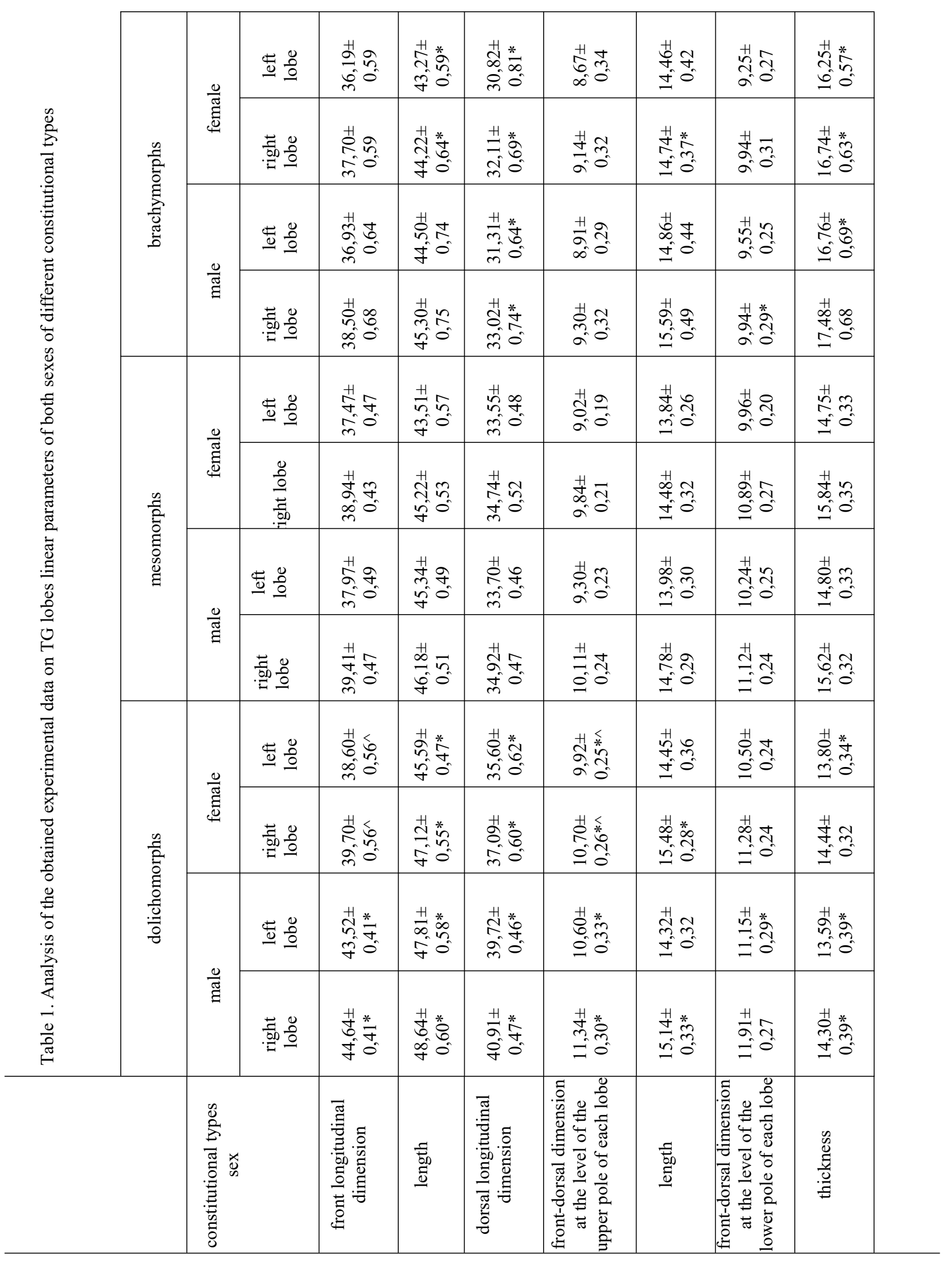

